\title{
Landslide Monitoring Point Optimization Deployment Based on Fuzzy Cluster Analysis
}

\author{
Zhaoyang Wang \\ College of Geology \& Environment, Xi'an University of Science and Technology, Xi'an, China \\ Email: wangzhaoyang1999@126.com
}

How to cite this paper: Wang, Z.Y. (2017) Landslide Monitoring Point Optimization Deployment Based on Fuzzy Cluster Analysis. Journal of Geoscience and Environment Protection, 5, 118-122. https://doi.org/10.4236/gep.2017.56012

Received: May 10, 2017

Accepted: June 12, 2017

Published: June 15, 2017

Copyright (C) 2017 by author and Scientific Research Publishing Inc. This work is licensed under the Creative Commons Attribution International License (CC BY 4.0).

http://creativecommons.org/licenses/by/4.0/

\section{cC) (†) Open Access}

\begin{abstract}
Landslide monitoring is one of the important means to landslide control. In order to do well this job in landslide monitoring work, first in ascertaining the geological conditions, then laying out a variety of professional monitoring points. This paper adopts the fuzzy cluster analysis method, and the landslide monitoring points by using fuzzy cluster analysis method, through the calculation of deformation of fuzzy clustering, finally draws the conclusion that the landslide monitoring point classification. The method for the landslide monitoring point optimization, as well as the landslide deformation monitoring plan modification and perfect have very important reference value.
\end{abstract}

\section{Keywords}

Landslide, Monitoring, Fuzzy Cluster, Optimization Deployment

\section{Introduction}

In recent years, research on landslide monitoring has been paid highly attention by researchers both at home and abroad, and significant progress has been made. At present, many landslides have carried out a wide range and costly professional monitoring work, professional monitoring means, and achieved a certain monitoring effect [1]. Zhang et al. (2007) based on the basic principle of time domain reflection test technology, proposed the field work method of time domain reflection test in landslide monitoring [2]. Miao et al. (2010) have made a comprehensive evaluation of the results of multi-model prediction of landslide displacement, so as to optimize the best model [3]. Zhu (2010) established a multidimensional model of landslide displacement monitoring, and data mining analysis on the basis of multidimensional data set [4].

To carry out landslide professional monitoring, the layout of the professional means of monitoring, first of all must be found on the basis of geological condi- 
tions. Based on the geological analysis, this paper analyzes the deployment of landslide professional monitoring points by fuzzy clustering analysis, and makes the related research on the optimization of landslide monitoring.

\section{Clustering Analysis}

The representativeness, accuracy, and reasonable setting of monitoring points are the key environments to ensure successful monitoring. Therefore, by optimizing the monitoring points, it is of great significance to obtain the monitoring quality of the maximum space with the least number of monitoring points. Based on the analysis results and the actual situation of the landslide, it can provide the basis for the optimization of the landslide monitoring points and the monitoring of the optimal distribution points [5]. There are many methods of cluster analysis; commonly used is system clustering method, stepwise clustering method and fuzzy clustering method. In this paper, fuzzy clustering analysis is used to analyze the deployment of landslide monitoring points.

\subsection{Fuzzy Clustering Analysis}

Landslide monitoring and analysis is the prerequisite and foundation of landslide prediction, and the results of landslide prediction are directly related to the distribution of monitoring points on landslide. In the landslide prediction, it is necessary to model the mathematical model based on the monitored data. It is a complicated and cumbersome to use the analysis of the points separately. Therefore, before the landslide monitoring point modeling, the fuzzy monitoring analysis of each monitoring point, mathematical modeling of each kind of monitoring points, and then use the built mathematical model for deformation analysis, which can reduce the follow-up calculation workload, so as to improve work efficiency. After fuzzy clustering, through the classification of deformation points, for understanding the landslide deformation of the partition has a very important reference value. The fuzzy clustering analysis procedure is as follows.

\subsection{Data Standardization}

Establish the data matrix: set the domain $U=\left\{x_{1}, x_{2}, \cdots, x_{n}\right\}$ for the classification of the object, each object by $m$ indicators that its character, that, $x_{i}=\left(x_{i 1}, x_{i 2}, \cdots, x_{i m}\right),(i=1,2, \cdots, n)$.

Thus, the original data matrix is

$$
\left[\begin{array}{cccc}
x_{11} & x_{12} & \cdots & x_{1 m} \\
x_{21} & x_{22} & \cdots & x_{2 m} \\
\vdots & \vdots & \ddots & \vdots \\
x_{n 1} & x_{n 2} & \cdots & x_{n m}
\end{array}\right]
$$

In practical problems, different data generally have different dimensions. In order to compare the amount of different dimensions, it is usually necessary to make appropriate changes to the data. There are generally translational standard 
deviation transform, translation range transformation and logarithmic transformation.

\subsection{Establish Fuzzy Similarity Matrix}

Set the domain to $U=\left\{x_{1}, x_{2}, \cdots, x_{n}\right\}, x_{i}=\left(x_{i 1}, x_{i 2}, \cdots, x_{i m}\right)$, according to the traditional clustering method to determine the similarity coefficient, the establishment of fuzzy similarity matrix. The method of calculating the similarity degree $r_{i j}=R\left(x_{i}, x_{j}\right)$ of $x_{i}$ and $x_{j}$ mainly uses the similarity coefficient method, distance method and other methods of traditional clustering analysis. According to the characteristics of the problem, select a different formula to calculate.

\subsection{Calculate the Fuzzy Equivalence Matrix}

According to the fuzzy matrix obtained by the calibration, only a fuzzy similarity matrix $R$ is not necessarily transitive, that is, $R$ is not necessarily a fuzzy equivalent matrix. In order to classify, it is also necessary to transform $R$ into a fuzzy equivalence matrix $R^{*}$. The quadratic method can be used to pass the closure $t(R)$, and the fuzzy similarity matrix is transformed into a fuzzy equivalent matrix.

Starting from the fuzzy similarity matrix $R$, the squares are obtained in turn, that is, $R \rightarrow R^{2} \rightarrow R^{4} \rightarrow \cdots \rightarrow R^{2^{i}} \rightarrow \cdots$, When the first occurrence of $R^{k} \circ R^{k}=R^{k} \quad$ (indicating $R^{k}$ is transitive), $R^{k}$ is the required transitive closure $t(R)$.

\section{Example Analysis}

The fuzzy clustering method is used to analyze a landslide body. In the landslide body is distributed with five monitoring points, the use of GPS every two months to monitor once. The data to be monitored are analyzed by fuzzy clustering analysis.

\subsection{Data Standardization}

1) Data matrix

Using the landslide GPS monitoring data, see Table 1.

Get the original matrix of landslide monitoring data, see Table 2.

2) Data standardization

Table 1. Landslide deformation monitoring point data tables.

\begin{tabular}{cccccccccccccc}
\hline monitoring point number & 1 & 2 & 3 & 4 & 5 & 6 & 7 & 8 & 9 & 10 & 11 & 12 \\
\hline P1 & 3.2 & 2.8 & 6.4 & 5.7 & 6.4 & 4.1 & 5.4 & 16.6 & 28.3 & 36.2 & 49 & 51.4 \\
P2 & 4.1 & 5.4 & 12 & 8.6 & 8.6 & 8.1 & 15 & 20.1 & 22.8 & 43.3 & 39.6 & 39.3 \\
P3 & 3.2 & 9.5 & 3.2 & 14.2 & 19 & 22 & 29.2 & 15.8 & 17.5 & 32.2 & 8.6 & 22.2 \\
P4 & 3 & 2.2 & 4.5 & 4.5 & 8.5 & 7.1 & 10.8 & 7 & 19.2 & 31.9 & 29.1 & 26.7 \\
P5 & 3.2 & 4.1 & 1 & 4.5 & 5.8 & 7.6 & 3 & 5 & 8.5 & 17 & 6.1 & 8.9 \\
\hline
\end{tabular}


The data are converted using the translation range method.

$$
x_{i k}^{\prime}=\frac{x_{i k}-\min _{1 \leq i \leq n}\left\{x_{i k}\right\}}{\max _{1 \leq i \leq n}\left\{x_{i k}\right\}-\min _{1 \leq i \leq n}\left\{x_{i k}\right\}} \quad(k=1,2, \cdots, m)
$$

3) After the data is standardized, see Table 3.

\subsection{Calibration (The Establishment of Fuzzy Similarity Matrix)}

Calculate the degree of similarity, where the maximum and minimum methods in the similarity coefficient method are used.

$$
r_{i j}=\frac{\sum_{k=1}^{m}\left(x_{i k} \wedge x_{j k}\right)}{\sum_{k=1}^{m}\left(x_{i k} \vee x_{j k}\right)}
$$

The similarity matrix $R=\left(r_{i j}\right)_{n \times n}\left[\begin{array}{cccc}r_{11} & r_{12} & \cdots & r_{1 n} \\ r_{21} & r_{22} & \cdots & r_{2 n} \\ \vdots & \vdots & \ddots & \vdots \\ r_{n 1} & r_{n 2} & \cdots & r_{n m}\end{array}\right]$ is calculated according to Equation (3). $r_{i j}$ indicates the degree of similarity between the $i$ and $j$ points.

Landslide monitoring point deformation fuzzy similarity matrix

$$
R=\left[\begin{array}{ccccc}
1 & 0.5402 & 0.2797 & 0.3278 & 0.0422 \\
0.5402 & 1 & 0.3793 & 0.4061 & 0.0799 \\
0.2797 & 0.3793 & 1 & 0.2889 & 0.0766 \\
0.3278 & 0.4061 & 0.2889 & 1 & 0.0457 \\
0.0422 & 0.0799 & 0.0766 & 0.0457 & 1
\end{array}\right]
$$

\subsection{Clustering (Calculate the Fuzzy Equivalence Matrix)}

The fuzzy equivalence matrix $R^{*}$ is calculated as: $R \circ R=R=R^{*}$.

From large to small $\lambda$ to cluster analysis.

When $\lambda=1, \mathrm{U}$ can be divided into five categories P1, P2, P3, P4, P5

Table 2. The original matrix of landslide monitoring data.

\begin{tabular}{cccccccccccc}
\hline 3.2 & 2.8 & 6.4 & 5.7 & 6.4 & 4.1 & 5.4 & 16.6 & 28.3 & 36.2 & 49 & 51.4 \\
4.1 & 5.4 & 12 & 8.6 & 8.6 & 8.1 & 15 & 20.1 & 22.8 & 43.3 & 39.6 & 39.3 \\
3.2 & 9.5 & 3.2 & 14.2 & 19 & 22 & 29.2 & 15.8 & 17.5 & 32.2 & 8.6 & 22.2 \\
3 & 2.2 & 4.5 & 4.5 & 8.5 & 7.1 & 10.8 & 7 & 19.2 & 31.9 & 29.1 & 26.7 \\
3.2 & 4.1 & 1 & 4.5 & 5.8 & 7.6 & 3 & 5 & 8.5 & 17 & 6.1 & 8.9 \\
\hline
\end{tabular}

Table 3. Data sheet normalized.

\begin{tabular}{cccccccccccc}
\hline 0.1818 & 0.0822 & 0.4909 & 0.1237 & 0.0455 & 0 & 0.0916 & 0.7682 & 1 & 0.73 & 1 & 1 \\
1 & 0.4384 & 1 & 0.4227 & 0.2121 & 0.2235 & 0.458 & 1 & 0.7222 & 1 & 0.7809 & 0.7153 \\
0.1818 & 1 & 0.2 & 1 & 1 & 1 & 1 & 0.7152 & 0.4545 & 0.5779 & 0.0583 & 0.3129 \\
0 & 0 & 0.3182 & 0 & 0.2045 & 0.1676 & 0.2977 & 0.1325 & 0.5404 & 0.5665 & 0.5361 & 0.4188 \\
0.1818 & 0.2603 & 0 & 0 & 0 & 0.1955 & 0 & 0 & 0 & 0 & 0 & 0 \\
\hline
\end{tabular}


When $\lambda=0.5402, \mathrm{U}$ can be divided into $\{\mathrm{P} 1, \mathrm{P} 2\},\{\mathrm{P} 3\},\{\mathrm{P} 4\},\{\mathrm{P} 5\}$

When $\lambda=0.4061, \mathrm{U}$ can be divided into P1, P2, P3, P4, P5

When $\lambda=0.3278, \mathrm{U}$ can be divided into $\{\mathrm{P} 1, \mathrm{P} 4\}, \mathrm{P} 2, \mathrm{P} 3, \mathrm{P} 5$

When $\lambda=0.2889, \mathrm{U}$ can be divided into $\mathrm{P} 1,\{\mathrm{P} 2, \mathrm{P} 4\}, \mathrm{P} 3, \mathrm{P} 5$

When $\lambda=0.2797, \mathrm{U}$ can be divided into $\{\mathrm{P} 1, \mathrm{P} 2, \mathrm{P} 3, \mathrm{P} 4\}, \mathrm{P} 5$

When $\lambda=0.0422, \mathrm{U}$ can be divided into P1, P2, P3, P4, P5.

In the actual monitoring situation, the $\mathrm{P} 1, \mathrm{P} 3$ and $\mathrm{P} 5$ monitoring points are located at the front, middle and trailing edges of the landslide, while the P2 and $\mathrm{P} 4$ points are located on both sides of the central monitoring point $\mathrm{P} 3$. From the classification of $\lambda$ results can be seen, when $\lambda=0.2889$, points $\mathrm{P} 2$ and $\mathrm{P} 4$ for a class, the other monitoring points were a class.

\section{Conclusion}

The fuzzy clustering analysis is used to analyze the continuous data of landslide monitoring and deformation, which is helpful to classify the deformation points of landslides. At the same time, in the monitoring, if the use of fuzzy clustering analysis and the deformation point of the cluster can greatly reduce the follow-up workload and improve work efficiency, in the practical application, due to the clustering analysis of $\lambda$ values is not easy to determine, so it's needed to combine the scene of the actual investigation of the landslide to monitor the classification of the points.

\section{References}

[1] Zhang, J.L., Xu, W.Y., Jin, H.Y., et al. (2009) Safety Monitoring and Stability Analysis of Large-Scale and Complicated High Rock Slope. Chinese Journal of Rock Mechanics and Engineering, 28, 1820-1827.

[2] Zhang, Q., Shi, Y.X. and Lin, J. (2007) Landslide Monitor Technique Based on TDR. Journal of Jilin University (Earth Science Edition), 37, 134-143.

[3] Miao, H.B., Yin, K.L., Xu, F., et al. (2010) Comprehensive Evaluation on Multiple Predictions of the Landslide Displacements Based on Component Analysis. Journal of Wuhan University of Technology, 32, 65-70.

[4] Zhu, C.H. and Hu, G.D. (2010) Data Mining in Landslide Monitoring Based on Multidimensional Modeling. Bulletin of Soil and Water Conservation, 30, 121-124.

[5] Wang, Z.Y. (2012) Study on the Effectiveness Evaluation Method of Landslide Monitoring and Forecast-A Case Study of Three Gorges Reservoir Region. Chengdu University of Technology, Chengdu. 
Submit or recommend next manuscript to SCIRP and we will provide best service for you:

Accepting pre-submission inquiries through Email, Facebook, LinkedIn, Twitter, etc. A wide selection of journals (inclusive of 9 subjects, more than 200 journals)

Providing 24-hour high-quality service

User-friendly online submission system

Fair and swift peer-review system

Efficient typesetting and proofreading procedure

Display of the result of downloads and visits, as well as the number of cited articles Maximum dissemination of your research work

Submit your manuscript at: http://papersubmission.scirp.org/

Or contact gep@scirp.org 